\title{
Plant Variety Protection in Sub-Saharan Africa: Balancing Commercial and Smallholder Farmers' Interests
}

\author{
B. (Bram) De Jonge ${ }^{1,2}$ \\ ${ }^{1}$ Law \& Governance Group, Wageningen University, Netherlands \\ ${ }^{2}$ Intellectual Property Unit, University of Cape Town, South Africa \\ Correspondence: B. (Bram) De Jonge, Law \& Governance Group, Wageningen University, Netherlands. E-mail: \\ bram.dejonge@wur.nl
}

Received: June 7, 2014 Accepted: June 30, 2014 Online Published: August 25, 2014

doi:10.5539/jpl.v7n3p100 URL: http://dx.doi.org/10.5539/jpl.v7n3p100

\begin{abstract}
Sub-Saharan African countries, through their regional organizations, have embarked on the harmonisation of plant variety protection (PVP) systems. These initiatives are largely modelled on the UPOV 1991 act, which claims to incentivize plant breeding and facilitate agricultural development. Civil Society Organisations (CSO), however, strongly criticise this process for being out of step with Sub-Saharan African agricultural realities, undermining smallholder farmers' agricultural practices and, ultimately, threatening food security. Among their main concerns are the fear that the proposed regimes facilitate biopiracy and lack recognition of farmers' rights. This article discussed three of the main CSO concerns in tandem with examples of alternative provisions from PVP systems from around the world. While it will be shown that the CSO concerns are not likely to be acted upon, this article aims to answer the pressing question whether a UPOV' 91 based PVP system hampers farming practices in developing countries, and explores several legal avenues to accommodate the needs and traditions of smallholder farmers.
\end{abstract}

Keywords: agriculture, farmers' rights, food security, intellectual property rights, plant breeding, plant variety protection, Sub-Saharan Africa

\section{Introduction}

The Agreement on Trade-Related Aspects of Intellectual Property Rights (TRIPS), adopted in 1995, sets minimum standards on the protection of intellectual property for member states of the World Trade Organisation (WTO). Of particular importance to agriculture is Article 27(3)b, which requires countries to "provide for the protection of plant varieties either by patents or by an effective sui generis system or by any combination thereof" (WTO, 1995). While protection of plant varieties is mandatory under TRIPS, the agreement offers member countries considerable flexibility in this regard. Not only does Article 27(3) permit selection of the means of protection (patents, a sui generis system or a combination of both) but also allows individual countries that choose a sui generis system to define for themselves the components of such system. For example, individual members are free to define the subject matter of protection (i.e. what is a plant variety), the requirements for protection, the scope of protection (e.g. whether harvested materials are included), and the duration of protection. The only requirement is that the system be "effective," which means at the very least that it provides for an intellectual property right (IPR).

The International Union for the Protection of New Varieties of Plants (UPOV) adopted its first convention in 1961 whereby it established a sui generis system specifically designed to provide intellectual property protection for plant varieties. UPOV provides legal protection based on specific requirements (e.g. distinctiveness) and exceptions (e.g. breeders' exemption) that, in contradistinction to patent law, take into account the biological nature of the protected subject matter and agricultural traditions. The UPOV convention was updated in 1972, 1978 and 1991, in order to remain consistent with developments in the professional breeding sectors of member countries. With the exception of South Africa and Argentina, all members were industrial countries at the time UPOV '91 was adopted (Louwaars, De Jonge, \& Munyi, 2013). New members to UPOV can only join the UPOV 1991 Act. Since the adoption of the TRIPS agreement in 1995 many least developed to lower middle income countries have joined UPOV, amounting to 23 of the 71 UPOV member countries in 2013. While some attribute this to the merits of the UPOV system and the convenience of being able to adopt a ready-made sui 
generis system, others point to obligations flowing from bilateral trade agreements with industrialized countries, or state that a "continued, relentless pressure from the UPOV Secretariat (implicit or explicit) has moved countries down the UPOV path" (Dutfield, 2011, p. 11).

The countries in Sub-Saharan Africa are no exception to this trend. In fact, developments in Sub-Saharan Africa have been driven by two regional organizations, the African Regional Intellectual Property Organisation (ARIPO) and the Southern African Development Cooperation (SADC), which have introduced initiatives to establish harmonized plant variety protection systems complying with UPOV ' 91 , the latest UPOV convention. The "Draft ARIPO Legal Framework for the Protection of New Varieties of Plants" (ARIPO, 2013a) and the SADC "Draft Protocol for the Protection of New Varieties of Plants (Plant Breeders' Rights) in the Southern African Development Community Region" (SADC, 2012) are very similarly structured and aligned with the UPOV 1991 Act.

It is worth noting that, at least according to the TRIPs agreement, Least Developed Countries (LDCs) are not under pressure to make these changes at this time. TRIPs allows for an extended implementation period for LDCs (Note 1), which now have till 2021 to comply with the TRIPS provisions (Note 2). It is also of significance that the latest UPOV convention was developed to fit the agricultural situation in the industrialised countries in 1991 - something very different from the current agricultural situation in many of the countries in Sub-Saharan Africa.

The ARIPO draft PVP policy states as a goal that in order to mitigate the prevailing agricultural outlook in Africa and to overcome the challenge of malnutrition on the continent, "African Governments must adopt national policies aimed at promoting agricultural research and development which will make available innovative solutions including high yielding and pest resistant food crop varieties.”(ARIPO, 2011, p. 3). It continues "Agricultural innovation has the potential to transform African agriculture but only if strong structures and measures that reward those who create new varieties are put in place to help disseminate critical best practices and technological breakthroughs." (ARIPO, 2011, p. 3). UPOV '91, seen as means whereby "strong structures" and "rewards" for "those who create new varieties" can be created, is the model chosen by both ARIPO and SADC. Their hope is that their draft legislation will encourage plant breeding and facilitate agricultural development, allowing farmers to access "a wide range of improved varieties to contribute to the attainment of the regional goal of economic development and food security" (ARIPO, 2013a, Preamble; SADC, 2012, Preamble).

However, not everyone agrees with this approach. More than 80 Civil Society Organizations (CSO) have strongly criticized the draft legislation piloted by ARIPO (CSOs, 2012) and SADC (CSOs, 2013) as being potentially disastrous for the agricultural systems of least developed member states. Among their main concerns are 1) the fear that biopiracy will be facilitated ,2) the lack of protection of farmers' rights, and 3) the non-appropriateness of the criteria for protection in the context of Sub-Saharan Africa. After a brief introduction of the ARIPO and SADC draft PVP laws, these three CSO concerns will be discussed in tandem with examples of alternative provisions from PVP systems from around the world. From this discussion, it will become clear that a solution to the first two CSO concerns (biopiracy and threatened farmers' rights) can be found through the creation of a hybrid PVP system that aims to balance the rights of plant breeders with those of farmers and traditional communities. Such a system establishes breeders' rights while incorporating obligations from, for example, the Convention on Biological Diversity and the International Treaty on Plant Genetic Resources for Food and Agriculture. Nevertheless, it will be shown that the CSO demand for such a hybrid PVP system is not likely to be honored by ARIPO and SADC.

The third CSO concern is not likely to be acted upon either, as this would counter the establishment of a harmonized PVP system that complies with the highest international standards, which is the key rationale for setting up these regional PVP systems in the first place. It is beyond the scope of this article to analyse whether a UPOV '91 based PVP system would indeed create incentives for investments in breeding and the development of a breeding industry in countries that so far lack a formal seed market. However, this article aims to answer the pressing question whether such PVP system could actually hamper existing agricultural systems and farming practices in Sub-Saharan Africa. Given the fact that - on the basis of a theoretical analysis - this question has to be answered in the affirmative, this article finally explores some legal avenues that can accommodate the needs and traditions of those many smallholder farmers in the region, which may well be adversely affected by the proposed PVP legal framework.

\section{The ARIPO and SADC Draft PVP Laws}

The SADC Food, Agriculture and Natural Resources Directorate has been working on a draft Protocol for the 
Protection of New Varieties of Plants in the SADC region for several years now. The latest version, which was circulated in November 2012, is closely aligned with the UPOV 1991 act. The Draft ARIPO Legal Framework for the Protection of New Varieties of Plants was approved during the 14th session of the Council of Ministers held in Uganda, November 2013, and it was found to be in conformity with the UPOV 1991 act by the UPOV Council in April 2014. ARIPO is now preparing a diplomatic conference in order to have the protocol officially adopted.

In both draft PVP laws and the UPOV 1991 act, a variety must be novel, distinct, uniform and stable to be eligible for protection. For a plant variety to be considered novel, it must not have been previously marketed for a specific time period (UPOV, 1991, Article 6; ARIPO, 2013a, Article 7; SADC, 2012, Article 7). Distinctiveness requires that the new plant variety must be clearly distinguishable from any other variety whose existence is a matter of common knowledge (UPOV, 1991, Article 7; ARIPO, 2013a, Article 8; SADC, 2012, Article 8). The uniformity requirement ensures that a new plant variety can be defined for the purpose of protection by being sufficiently 'uniform' in its relevant characteristics (UPOV, 1991, Article 8; ARIPO, 2013a, Article 9; SADC, 2012, Article 9). And the new variety needs to be stable so that it remains true to type after repeated cycles of propagation (UPOV, 1991, Article 9; ARIPO, 2013a, Article 10; SADC, 2012, Article 10). Furthermore, both draft PVP systems provide protection for all genera and species, and the period of protection is 25 years for grapevines and trees and 20 years for all other plants (UPOV, 1991, Article 3 \& 19; ARIPO, 2013a, Article 3 \& 26; SADC, 2012, Article $3 \& 25$ ). With respect to the scope of plant breeders' rights, the authorisation of the plant breeder is required for various uses including the production or multiplication of the protected variety, for exporting and importing, and for its selling, marketing or offering for sale (UPOV, 1991, Article 14; ARIPO, 2013a, Article 21; SADC, 2012, Article 26).

With respect to the exceptions to the rights of plant breeders, both the ARIPO and SADC drafts contain a breeders' exemption and farmers' privilege comparable to those found in UPOV ' 91 . The breeders' exemption allows protected varieties to be freely used for the purpose of breeding new varieties thereby allowing any breeder to have access to the latest improvements and new variation (UPOV, 1991, Article 15.1.iii; ARIPO, 2013a, Article 22.1.iii; SADC, 2012, Article 27.c). The farmers' privilege, as included in the UPOV 1991 Act, is an optional exception that permits farmers to save and reuse seed of a protected variety on their own farm "within reasonable limits and subject to the safeguarding of the legitimate interests of the breeder" (UPOV, 1991, Article 15.2). The SADC and ARIPO draft PVP laws employ different strategies to protect these "legitimate interests of the breeder": The ARIPO draft only provides a farmers' privilege for specific agricultural crops and vegetables with a history of seed-saving, which will be listed by the Administrative Council. Specifically excluded are fruits, ornamentals, other vegetables or forest trees (ARIPO, 2013a, Article 22.2). The SADC draft protocol uses the term 'subsistence farmers' to designate a specific category of farmers who alone are the beneficiary of the farmers' privilege (SADC, 2012, Article 27.d).

\section{CSO Concerns}

\subsection{Fighting Biopiracy and Securing Benefit-Sharing}

One key concern of the CSOs with respect to the ARIPO and SADC draft PVP laws is the lack of concrete mechanisms to prevent misappropriation of genetic resources and associated traditional knowledge. Even more so, they fear that the proposed PVP regimes will actually facilitate such misappropriation arguing that foreign breeding companies can apply for exclusive rights on new varieties that may well have been created by use of local germplasm. In order to prevent this possibility and fight biopiracy some countries have incorporated additional requirements for granting breeders' rights whose aim is to facilitate the sharing of the benefits derived from the utilisation of genetic resources as stipulated by the Convention on Biological Diversity (UN, 1992) and the Nagoya Protocol (UN, 2010). India, for example, requires applicants to include a "declaration that the genetic material or parental material acquired for breeding, evolving or developing the variety has been lawfully acquired" (India, 2001, Article 13.h), alongside "a complete passport data of the parental lines from which the variety has been derived along with the geographical location in India from where the genetic material has been taken and all such information relating to the contribution, if any, of any farmer, village community, institution or organisation in breeding, evolving or developing the variety" (Article 18.e, also see Article 40). Upon registration of the variety, the relevant authority will invite "claims of benefit sharing" and determine the amount of benefit-sharing due (Article 26). Similar provisions can be found in the PVP laws of Malaysia, Costa Rica and Thailand.

\subsection{Protecting Farmers' Rights}

The concerns relating to biopiracy and benefit-sharing are part of a wider concern that the rights of farmers are 
marginalised and subordinated to the rights of breeders in the current SADC and ARIPO draft PVP laws. Of the 24 countries that are parties to either the SADC, ARIPO or both, 19 are a party to the International Treaty on Plant Genetic Resources for Food and Agriculture (ITPGRFA) of the Food and Agriculture Organisation (FAO) (Note 3), which obliges Parties to take measures to protect and promote farmers' rights. According Article 9 of the ITPGRFA, farmers' rights include protection of traditional knowledge relevant to plant genetic resources for food and agriculture, the right to equitably participate in sharing benefits arising from the utilization of plant genetic resources, and the right to participate in making decisions at the national levels on matters related to the conservation and sustainable use of plant genetic resources for food and agriculture (FAO, 2001, Article 9.2). Another aspect, generally considered the most essential part of the farmer's rights debate, is the right to save, use, exchange and sell farm-saved seed. According to the ITPGRFA, the right to save, use and exchange is "subject to national law and as appropriate" (Article 9.3). This implies that the implementation of a strict plant variety protection law could strongly limit these farmers' rights with respect to protected varieties.

Some countries have tried to ensure that farmers' rights are not undermined by the introduction of breeders' rights. Approximately a decade ago, this was also the case in Sub-Saharan Africa as all ARIPO and SADC member countries supported the "African Model Legislation for the Protection of the Rights of Local Communities, Farmers and Breeders, and for the Regulation of Access to Biological Resources". This African model law, which was endorsed by the Heads of State of the Organization of African Unity (OAU) in Algeria in 2000, aims to "recognize, protect and support the inalienable rights of local communities including farming communities over their biological resources, knowledge and technologies", and also to "recognize and protect the rights of breeders" (OAU, 2000, Objectives). To that end, the model law describes in detail the rights of communities (part IV) and farmers (part V). Regarding the issue of farmer saved seed, the African Model Law allows farmers to "collectively save, use, multiply and process farm-saved seed of protected varieties." (Article 26). It further states that farmers shall not sell farm-saved seed of a protected variety in the seed industry on a commercial scale. Although some African countries have incorporated parts of the African Model Law in their (draft) PVP laws, the model legislation has mainly been ignored.

\subsection{The Criteria for Protection}

A third issue relates to the criteria for protection contained within the ARIPO and SADC draft PVP legislation. These criteria are based on the standards for novelty, distinctness, uniformity and stability (NDUS) incorporated in the UPOV 91 Act. In their statement of concerns, the CSOs question the appropriateness of these criteria in Sub-Saharan Africa for several reasons: the novelty requirement for exclusively focussing on commercial novelty; the criteria for distinctness which contain a very low threshold for inventiveness; the uniformity standard for leading to erosion of genetic diversity and, thus, increasing genetic vulnerability; and the uniformity and stability requirements making it very difficult for farmer varieties to be eligible for protection.

One proposal is to replace the UPOV standards for uniformity and stability by 'identifiability', i.e., describing a typical combination of characteristics of the new plant variety in order to fulfil the legal need to identify the protected subject matter without prescribing the physical properties a plant variety needs to have (Rangnekar, 2002; IPGRI, 1999; Leskien \& Flitner, 1997). This approach would make it possible to have protection of plant varieties or groupings that are more heterogeneous and variable, like landraces and farmer varieties. Such varieties are deemed very important for food security because of their heterogeneous and unstable characteristics that fit local agro-ecological conditions and can respond to changing conditions in the face of climate change. Malaysia has included 'identifiability' in its PVP law as it allows a plant variety that is "bred, or discovered and developed by a farmer, local community or indigenous people," to be registered and "granted a breeder's right if the plant variety is new, distinct and identifiable" (Malaysia, 2004, Article 14). A plant variety is considered identifiable if "(i) it can be distinguished from any other plant grouping by the expression of one characteristic and that characteristic is identifiable within individual plants or within and across a group of plants; and (ii) such characteristics can be identified by any person skilled in the relevant art".

\section{A Hybrid PVP System}

By raising the first two concerns, the fight against biopiracy and for farmers' rights, the CSOs aim for one and the same objective: the balancing of breeders' rights with the rights of farmers and traditional communities through the creation of a hybrid PVP system that, next to establishing and safeguarding the rights of plant breeders, incorporates international obligations deriving from the Convention on Biological Diversity (CBD) and the ITPGRFA. As mentioned above, TRIPS allows its members to create their own sui generis systems, which, for example, could establish IP protection over new plant varieties while securing that access and benefit-sharing procedures are adhered to and farmers' rights are recognized. Such hybrid systems have been drafted by several 
countries as has been discussed above.

Yet despite the ready availability of these examples, it seems very unlikely that SADC or ARIPO will be moving towards such hybrid PVP systems by incorporating the relevant aspects of either the CBD or ITPGRFA into their current legal frameworks. For example, ARIPO's draft PVP policy refers to both the ITPGRFA and CBD and mentions the importance of farmers' rights and the lawful acquirement of access to plant genetic resources and associated traditional knowledge in accordance with Article 15 of the CBD (ARIPO 2011, Article 36). Nevertheless, this apparent support of ITPGRFA and CBD principles is not unqualified as the ARIPO draft policy also states that "the determination of access to genetic resources rests with national governments and is subject to national legislations dealing with the grant of breeder's rights."

In fact the ARIPO draft PVP policy explicitly distinguishes between plant variety protection and legislation governing access to genetic resources and traditional knowledge by stating:

Since the legislation on access to genetic resources and the legislation dealing with the grant of breeder's rights pursue different objectives, have different scope of applications and require different administrative structures to monitor their implementation, it would be appropriate to provide separate legislations to address the issues although such legislations should be compatible and mutually supportive. (Article 36)

The Swakopmund Protocol on the Protection of Traditional Knowledge and Expressions of Folklore is seen as such 'separate legislation' dealing with the protection of traditional knowledge and genetic resources within the ARIPO region (ARIPO, 2010).

The above position to clearly distinguish and separate PVP legislation from legal obligations that derive from other international treaties regarding plant genetic resources is not something new. In fact, this standpoint has strongly been supported by the UPOV secretariat for many years. In UPOV's communications with the CBD secretariat it has been repeatedly emphasized that the objective of UPOV is to stimulate innovation in plant breeding, and that it is not an instrument for access and benefit-sharing (UPOV, 2009a). For example, communications discussing the aforementioned disclosure requirements to fight biopiracy in the Indian PVP legislation (see section 3.1 above) conclude that the UPOV secretariat "could not accept this as an additional condition of protection since the UPOV Convention (...) does not allow any further or different conditions for protection." (UPOV, 2009a).

\section{For and Against a Harmonised PVP System}

Future changes in the ARIPO and SADC PVP legislation in response to CSO concerns regarding the criteria of protection are equally unlikely. Apart from content related objections to the alternatives discussed above (Note 4), the key issue is that any amendment to the two proposed legal frameworks in terms of the criteria for protection would be in conflict with UPOV ' 91 . In addition, one of the most important rationales for setting up a regional PVP system is to provide a 'one stop shop' approach whereby a single protection title will cover all contracting parties, reducing costs and administrative hurdles for breeders, allowing varieties to be available in more countries, and facilitating effective synergies in the (technical) operations of national systems (ARIPO, 2012). Once countries within a region choose divergent standards of protection this rationale would be negated.

Obviously, the main objective of the SADC and ARIPO draft PVP laws is to create a regional PVP system that is fully in tune with the highest international standard "to boost agricultural production and develop the agri-business value chain for economic growth" (ARIPO, 2012). Yet, it is exactly the push for a harmonized PVP system that meets with much criticism. The CSOs essential claim is that such a 'one-size-fits-all' UPOV '91 based regime is unsuitable for the needs of individual member countries and their farmers, and does not consider the different levels of development among the member countries:

The approach assumes that what works for one country in the region (e.g. South Africa), should work for another country in the same region (e.g. Democratic Republic of Congo). Consequently, the draft Protocol also fails to provide any sort of flexibility to its most vulnerable members to enable them to address their specific socio-economic challenges. (CSOs, p. 5)

It appears that proponents of the current draft frameworks base their opinions on the idea that the needs of breeders of modern varieties, at least in terms of intellectual property protection, are the same everywhere, and that a high level of protection is essential for a breeding industry to take root and flourish. It goes beyond the scope of this article to assess whether a UPOV ' 91 based legislation does indeed create incentives for investments in breeding and the development of a breeding industry in countries that so far lack a formal seed market. However, the pressing question that needs to be answered is whether a UPOV '91 based PVP system 
could actually hamper existing agricultural systems and farming practices in the countries in question.

\section{Can a UPOV '91 Based PVP System Hamper Farming Practises in Developing Countries?}

The current discussion between proponents and opponents of a UPOV ' 91 based PVP system can be considered, to some extent at least, an ideological one as it seems rooted in fundamentally conflicting worldviews on the ways farming and agriculture should be organised. This clash can be summarized as the battle for control over genetic resources. Proponents of the current harmonization processes seem to take it for granted that you need to establish private ownership and build markets in order to generate investments and innovation in agriculture, which will then lead to economic welfare and food security. The opponents, on the other hand, condemn this as the privatisation and monopolisation of genetic resources that have always belonged to local farming communities and which depend on the control over these resources through seed saving and sharing, in favour of the private gains of a global seed industry and, in particular, a few multinationals (Note 5).

This fundamental discussion could strongly benefit from empirical data on the actual effects of a UPOV '91 based PVP law on the different agricultural systems in developing countries. So far, however, very little empirical research has been done in this area. UPOV itself has published one report on the impact of plant variety protection in five countries, including some developing counties (UPOV, 2005). However, this study does not consider the informal seed sector and is, therefore, of little use for answering the aforementioned question (Note 6). Other studies that do discuss UPOV '91 in relation to informal seed systems in developing countries have warned about potential negative impacts but these warnings have not been backed by strong empirical evidence, essentially because few developing countries have adopted and implemented a UPOV '91 based PVP system for many years (Louwaars et al., 2005; The Crucible II Group, 2000). In the absence of empirical data, could a theoretical analysis lead to an answer to our question whether a UPOV '91 based PVP system can hamper agricultural systems and farming practices in developing countries?

Both the proponents and opponents of a UPOV '91 based PVP system agree that smallholder farming, and the informal seed sector, is dominant in Sub-Saharan Africa (ARIPO, 2011; CSOs, 2012). Indeed, smallholder farms, when defined as being 2 hectares or less, represent $80 \%$ of all farms and contribute up to $90 \%$ of food production in some Sub-Saharan Africa countries (Wiggins, 2009; Livingston, Schonberger, \& Delaney, 2011). Because the formal sector can only cater for approximately $10 \%$ of total seed demand, these farmers are highly dependent on the customary practices of using farm-saved seed, exchanging seed amongst themselves, or trading seed on local grain markets (Maredia et al., 1999). Also for improved varieties, smallholder farmers source their seed mainly from the informal sector, which apart from its physical availability also keeps seed affordable (Louwaars \& De Boef, 2012). The latter reason also explains why a significant number of farmers in Africa acquire their seed from the local grain market, a risky practice given the fact that they often cannot reliably identify the variety they are purchasing (Lipper, Anderson, \& Dalton, 2010). These local markets provide those famers that have some surplus of seed to sell with a little extra income. A recognized benefit of these farmer-to-farmer practices of seed saving and exchange is that they contribute to the conservation and development of locally adapted crops that fit the specific (and often challenging) agro-ecological conditions in which these farmers have to operate (Lipper et al., 2010).

Given that saving and exchanging seed is the main source of seed for smallholder farmers in Sub-Saharan Africa, it seems only logical to conclude that any PVP system that would effectively ban such practices is likely to have a strong negative impact on smallholder farmers' livelihoods and on national food security, especially because the burden for food production in these countries is still on smallholder farmers. Of course, the reality is that any such PVP system would not affect the existing landraces and traditional varieties used by smallholder farmers as it only applies to the newly developed (modern) varieties that fulfil the stipulated criteria for protection. Indeed, in a response to the CSO concerns, ARIPO emphasises that "With regard to landraces, subsistence farmers will be able to continue what they were used to do." (ARIPO, 2013b, p. 6).

In addition, ARIPO refers to the farmers' privilege as the instrument whereby farmers can be allowed to save and reuse seed of a protected variety on their own holding. Furthermore, in the Implementation Regulations, which are yet to be drafted, the SADC and ARIPO regions could exempt small farmers from being required to pay remuneration to the breeder (Note 7). This approach has already been utilised by the European Council Regulation on Community Plant Variety Rights, which includes a list of crops for which farmers are allowed to use their own farmer saved seed and for which they "pay an equitable remuneration" to the PVP holder (European Council, 1994, Article 14). This is normally about 50\% of the commercial royalty (Ghijsen, 2007). Small farmers, however, are exempt from such payment, with small farmers being defined as "farmers who do not grow plants on an area bigger than the area which would be needed to produce 92 tonnes of cereals", or 
comparable criteria for other plant species (European Council, 1994, Article 14).

If ARIPO and SADC follow through with the above approach, the practice of smallholder farmers to use farm-saved seed on one's own farm will not be hampered by the introduction of a UPOV '91 based PVP system. However, the other two farming practices on which small farmers in developing countries are highly dependent 'over the fence' seed exchange and local seed trade, are not covered by the farmers' privilege. In their response to the CSO concerns, ARIPO, referring to UPOV Article 15.1.i discussed below, states that "Subsistence farming will be covered by the exception for private and non-commercial purposes." (ARIPO, 2013b, p. 6). Since 'subsistence farming' is not further defined it remains unclear what farming practices (i.e. seed saving, seed exchange, local trade) are actually covered by this exemption.

Article 15.1.i of the UPOV '91 act holds that the breeder's right shall not extend to acts done "privately and for non-commercial purposes." In order to clarify the meaning of this term, UPOV's explanatory note on Article 15.1.i states the following:

the propagation of a variety by a farmer exclusively for the production of a food crop to be consumed entirely by that farmer and the dependents of the farmer living on that holding, may be considered to fall within the meaning of acts done privately and for non-commercial purposes. Therefore, activities, including for example "subsistence farming", where these constitute acts done privately and for non-commercial purposes, may be considered to be excluded from the scope of the breeder's right, and farmers who conduct these kinds of activities freely benefit from the availability of protected new varieties. (UPOV, 2009b, p. 5)

UPOV's explanatory note does not mention the issue of exchange. It only refers to the propagation of a variety by a farmer for the production of a food crop "to be consumed entirely by that farmer and the dependents of the farmer living on that holding" (UPOV, 2009b, p. 5, italics added). This specific formulation makes it very unlikely that the exemption is meant to allow part of that food crop (e.g. grain to be used as seed) to be exchanged with anyone beyond the holding of the farmer that propagates it. Also, practices such as the selling and trading of seed surpluses on the local grain market cannot be considered to fall within the boundaries of the private and non-commercial use exemption. This implies that, where protected varieties are concerned, local seed trade and 'over the fence' seed exchange will be illegal in the ARIPO and SADC countries once their draft PVP laws are adopted.

\section{Legal Avenues to Incorporate Farming Practices of Smallholder Farmers in a UPOV '91 Based PVP System (Note 8)}

In order to accommodate the needs and traditions of smallholder farmers, and in recognition of the importance of informal seed systems for the provision of seed and the conservation of agro biodiversity, some proposals have been made to adapt UPOV ' 91 in such a way that the exchange of farm-saved seed for certain crops and/or farmers is permitted. Ghijsen, for example, proposes a separate PVP right for open pollinated food crops, with a weaker scope of protection to allow for the use and exchange of farmer saved seed. In order to fulfil the obligations of UPOV '91, the remuneration of the breeder could be arranged by means of a central fund from which the breeder gets paid on the basis of the acreage of the protected variety that is grown by farmers. The endowment for the fund could either be raised by the government or the farmers or both (Ghijsen, 1998).

Another proposal relates to the previously discussed private and non-commercial use exception in UPOV '91. Since the sharing and exchange of farm-saved seed between smallholder farmers in developing countries is of no commercial importance, but indeed of great importance for food security and conservation, expanding the private and non-commercial use exemption to all resource-poor farmers in order to enable them to exchange seed among their peers has been recommended (De Jonge, Tumushabe, Barungi, \& Louwaars, 2011). In a response to this study, the Dutch government stated that it will:

Urge for greater scope for the 'private and non-commercial use exemption' in UPOV 1991 than is currently the case. This will allow small farmers that use protected varieties to trade their surpluses on the market and exchange seed among themselves. (Bleker, 2012)

To allow smallholder farmers to trade their surpluses of a protected variety on the market would obviously require a clarification of the definition of 'non-commercial use'.

Another way to achieve the same goal is to broaden the farmers' privilege to include seed exchange and possibly also small non-commercial seed trade. Several countries have indeed incorporated a broader farmers' privilege in their PVP legislation. One example is provided by the Philippines. The Philippines are not currently a UPOV member but the country has initiated the procedure for acceding to the UPOV Convention (UPOV, 2013). The 
2002 PVP act includes several provisions that are derived from UPOV '91, such as those relating to essentially derived varieties. Nevertheless, the act has incorporated a much broader farmers' privilege, which holds that plant variety protection shall not extend to:

The traditional right of small farmers to save, use, exchange, share or sell their farm produce of a variety protected under this Act, except when a sale is for the purpose of reproduction under a commercial marketing agreement. The Board shall determine the condition under which this exception shall apply, taking into consideration the nature of the plant cultivated, grown or sown. (Philippines, 2002, Article 43)

A more elaborated example is provided by the Malaysian PVP act of 2004. Like the Philippines, Malaysia is not a UPOV member but has initiated the procedure for acceding to the UPOV Convention (UPOV, 2013). The Malaysian PVP act includes in its exceptions to the breeder's right:

(d) any act of propagation by small farmers using the harvested material of the registered plant variety planted on their own holdings;

(e) any exchange of reasonable amounts of propagating materials among small farmers; and

(f) the sale of farm-saved seeds in situations where a small farmer cannot make use of the farm-saved seeds on his own holding due to natural disaster or emergency or any other factor beyond the control of the small farmer, if the amount sold is not more than what is required in his own holding. (Malaysia, 2004, Article 31)

In a background document to the Malaysian PVP act a small farmer is defined as a "farmer with the size of land of holding for farming operations not exceeding 0.2 hectare." (Malaysia, n.d., p. 14).

In regard to Sub-Saharan Africa, one example is provided by Zambia. The Zambian PVP act provides that "A farmer may save, exchange or use part of the seed from the first crop of a plant which the farmer has grown for sowing in the farmer's farm to produce a second and subsequent crop." (Zambia, 2007, Article 8.2). With respect to commercial exchange, the legislation holds that notwithstanding the existence of a plant breeder's right on a plant variety, "any person or farmer may sell within a farm or any other place at which any plant of the plant variety are grown, any plant or propagating material of the variety at that place" (Article 8.1.c). This provision appears to cover those situations where farming is undertaken communally, allowing for seed exchange and trade on a local scale.

A final example comes from Ethiopia, which is currently in the process of developing a Plant Breeders' Rights Act. The current draft bill defines 'commercial market' in order to explicitly exclude trade between smallholder farmers. A smallholder farmer is then defined with reference to income levels, with total earnings from sales of farm-saved seed not exceeding the average household income. The draft proclamation includes a provision on farmers' rights, emphasizing that smallholder farmers have the right to save, use, exchange and sell farm-saved seed of any variety on the non-commercial market. In addition, a list of crops is included for which all other farmers have the right to save and use farm-saved seed on their own holding. In this way, three levels of rights are created: 1) For some crops breeders get full protection with no rights for farmers to save seed; 2) For all other crops breeders get protection but farmers have the right to reproduce seed on their own holding; 3) For all crops, smallholder farmers have the right to exchange and sell seed amongst themselves.

\section{Conclusion}

The development of a harmonized PVP system for Sub-Saharan Africa seems inevitable as the regional processes within SADC and, in particular, ARIPO are well on track. Given the fact that one of the main rationales for this development is to create a regional system that complies with the highest international standard in order to facilitate the introduction of foreign varieties and international trade (Note 9), it is also very unlikely that these regional organisation will adopt anything different from the standards set by UPOV ' 91 .

The concerns about these processes are manifold and include fears that the proposed regimes facilitate biopiracy and lack recognition of farmers' rights. On the basis of a theoretical analysis, we conclude that a UPOV '91 based PVP system can indeed hamper the practices of smallholder farmers to exchange and trade seed amongst themselves when protected varieties are concerned. Given the fact that exchanging and trading farm-saved seed is the main source of seed for smallholder farmers who represent $80 \%$ of all farms and carry the burden for food production in Sub-Saharan Africa, it is likely that the current ARIPO and SADC PVP frameworks will continue to face resistance. Not only by the $80+$ civil society organisations that have already voiced their concerns, but ultimately also by the parliaments of individual member countries that will have to approve becoming a party to the regional PVP system. 
Alternative legal avenues have been proposed to balance commercial and smallholder farmers' interests by recognizing the importance of informal seed systems for the provision of seed and the conservation of agro biodiversity. Given the importance of UPOV for setting international standards, the main question is to what extent the alternatives described above would still comply with the relevant provisions of the UPOV '91 Act. Since the farmers' privilege is defined very strictly and narrowly, little leeway seems to exist for countries to broaden this exception to the breeder's right and still fulfil UPOV'91 requirements. Also, UPOV's Article 15.1.i, which holds that the breeder's right shall not extend to acts done privately and for non-commercial purposes, is currently interpreted in too restrictive a manner to allow for the exchange of protected varieties amongst smallholder farmers.

Is it possible that this can change? The UPOV convention has changed over time and can be expected to change further. It seems likely that a new UPOV Convention will be adopted in the future with updated standards, probably containing provisions that better reflect the agricultural realities in developing countries, particularly as they are likely to become a dominant group within UPOV. The proposed legal avenues would make it easier for Sub-Saharan countries to establish a PVP system that protects the interests of breeders, in line with the highest international standards, while at the same time protecting and preserving the needs of those who make up the single largest group of farmers in a region - the smallholder farmers.

\section{Acknowledgements}

This work is part of the research programme Responsible Innovation, which is financed by the Netherlands Organisation for Scientific Research (NWO). I would like to thank my colleagues at Wageningen University and the University of Cape Town, in particular Peter Munyi and Bernard Maister, for their constructive and valuable comments. Any mistakes remain my own.

\section{References}

African Centre for Biosafety (ACB). (2012). Harmonisation of Africa's seed laws: a recipe for disaster- Players, motives and dynamics. Agriculture, Energy and Livelihood Series. Melville: ACB.

African Regional Intellectual Property Organisation (ARIPO). (2010). Swakopmund protocol on the protection of traditional knowledge and expressions of folklore. Retrieved from http://www.wipo.int/wipolex/en/treaties/text.jsp?file_id=201022

African Regional Intellectual Property Organisation (ARIPO). (2011). Draft regional policy and legal framework for plant variety protection. ARIPO-CM-XIII-8. Retrieved from http://www.aripo.org/index.php/2013-04-09-09-05-22/patents-utility-models/viewcategory/1-council-of-mi nisters-13th-session

African Regional Intellectual Property Organisation (ARIPO). (2012, November 1). Statement of ARIPO at the opening of the forty-sixth ordinary session of UPOV. Retrieved from http://www.ip-watch.org/2012/11/05/upov-hails-benefits-of-plant-variety-protection-civil-society-frustrated/

African Regional Intellectual Property Organisation (ARIPO). (2013a). Draft ARIPO legal framework for the protection of new varieties of plants. ARIPO-CM-XIV-8-ANNEX-II. Retrieved from http://www.ip-watch.org/2013/11/28/critical-moment-for-africas-small-farmers-as-aripo-decides-on-plant-v ariety-protection/

African Regional Intellectual Property Organisation (ARIPO). (2013b). Regional workshop on the ARIPO legal framework for the protection of new varieties of plants. Lilongwe, Malawi: Ufulu Gardens. ARIPO-CM-XIV-8-ANNEX-I. Retrieved from http://www.ip-watch.org/2013/11/28/critical-moment-for-africas-small-farmers-as-aripo-decides-on-plant-v ariety-protection/

African Regional Intellectual Property Organisation (ARIPO). (2013c). List of agricultural crops. ARIPO-CM-XIV-8-ANNEX-III. Retrieved from http://www.ip-watch.org/2013/11/28/critical-moment-for-africas-small-farmers-as-aripo-decides-on-plant-v ariety-protection/

Bleker, H. (2012, August 13). Reaction to study 'harnessing intellectual property rights for development objectives". Letter to parliament of the Minister for Agriculture and Foreign Trade. Unauthorized translation retrieved from http://www.apbrebes.org/news/dutch-minister-supports-differentiated-approach-pvp

Civil Society Organisations (CSOs). (2012). Civil society concerned with ARIPO's draft regional policy and 
legal framework for plant variety protection. Retrieved from http://www.acbio.org.za/index.php/media/64-media-releases/409-aripospvp-law-undermines-farmers-rightsa-food-security-in-africa

Civil Society Organisations (CSOs). (2013). Civil society concerned with the draft protocol for the protection of new varieties of plants (plant breeders' rights) in the southern African development community region $(S A D C)$ Retrieved from http://www.ip-watch.org/2013/04/05/african-regional-plant-varietyprotection-draft-legislation-raises-protest /

De Jonge, B. (2013). Possibilities for a differentiated PVP regime. In M.T. Mahop, B. De Jonge, \& P. Munyi, Seed systems and intellectual property rights: an inventory from five Sub-Saharan African countries (pp. 44-54). Report for the Ministry of Economic Affairs, Agriculture and Innovation, the Netherlands. Retrieved from http://www.wageningenur.nl/en/Publication-details.htm?publicationId=publication-way-3433339363734

De Jonge, B., Tumushabe, G., Barungi, J., \& Louwaars, N.P. (2011). Agricultural seeds that reduce hunger and poverty - Policies, perceptions and practices in intellectual property rights. In Harnessing intellectual property rights for development objectives: The double role of IPRs in the context of facilitating MDGs no. 1 and 6 (pp. 111-267). Nijmegen: Wolf Legal Publishers.

Dutfield, G. (2011). Food, biological diversity and intellectual property: The role of the international union for the protection of new varieties of plants (UPOV). Intellectual property issue paper no. 9. Geneva: QUNO. Retrieved from http://www.quno.org/resource/2011/2/food-biological-diversity-and-intellectual-property

European Council. (1994). Council regulation (EC) no 2100/94 of 27 July 1994 on community plant variety rights. Retrieved from http://www.cpvo.europa.eu/main/en/home/community-plant-variety-rights/legislation-in-force

Food and Agriculture Organisation of the United Nations (FAO). (2001). International treaty on plant genetic resources for food and agriculture (ITPGRFA). Retrieved from http://www.planttreaty.org/content/texts-treaty-official-versions

Ghijsen, H. (1998). Plant variety protection in a developing and demanding world. Biotechnology and Development Monitor 36(1), 2-5.

Ghijsen, H. (2007). Plant breeder's rights: a fair and balanced intellectual property right for plant varieties. Tailoring Biotechnologies, 3(2), 79-98.

India. (2001). The protection of plant varieties and farmers' rights act. Retrieved from http://www.wipo.int/wipolex/en/details.jsp?id=2401

International Plant Genetic Resources Institute (IPGRI). (1999). Key questions for decision-makers: Protection of plant varieties under the WTO agreement on trade-related aspects of intellectual property rights. Rome, Italy: IPGRI.

International Union for the Protection of New Varieties of Plants (UPOV). (1991). Act of 1991 - International convention for the protection of new varieties of plants. Retrieved from $\mathrm{http}: / /$ www.upov.int/upovlex/en/acts.html

International Union for the Protection of New Varieties of Plants (UPOV). (2005). UPOV report on the impact of plant variety protection. Geneva: UPOV.

International Union for the Protection of New Varieties of Plants (UPOV). (2009a). UPOV reply of January 23, 2009 , to the letter of the executive secretary of the secretariat of the convention on biological diversity (CBD) of December 19, 2008. Retrieved from http://www.upov.int/about/en/key_issues.html

International Union for the Protection of New Varieties of Plants (UPOV). (2009b). Explanatory notes on exceptions to the breeder's right under the 1991 act of the UPOV convention. Retrieved from $\mathrm{http}: / /$ www.upov.int/explanatory_notes/en/

International Union for the Protection of New Varieties of Plants (UPOV). (2013). Status in relation to the international union for the protection of new varieties of plants (UPOV) as of July 30, 2013. Retrieved from http://www.upov.int/export/sites/upov/members/en/pdf/status.pdf

Kloppenburg, J.R. (2005). First the seed: The political economy of plant biotechnology. Madison, WI: University of Wisconsin Press. 
Leskien, D. \& Flitner, M. (1997). Intellectual property rights and plant genetic resources: Options for a sui generis system. Issues in Genetic Resources No. 6. Rome: IPGRI.

Lipper, L., Anderson, C.L., \& Dalton, T.J. (Eds). (2010). Seed trade in rural markets. Implications for crop diversity and agricultural development. London: Earthscan.

Livingston, G., Schonberger, S., \& Delaney, S. (2011). Sub-Saharan Africa: The state of smallholders in agriculture. Paper presented at the IFAD conference on new directions for smallholder agriculture, 24-25 January. Rome: IFAD.

Louwaars, N.P., \& De Boef, W.S. (2012). Integrated seed sector development in Africa: A conceptual framework for creating coherence between practices, programs, and policies. Journal of Crop Improvement, 26, 39-59. http://dx.doi.org/10.1080/15427528.2011.611277

Louwaars, N.P., De Jonge, B., \& Munyi, P. (2013). Intellectual property rights in the plant sciences and development goals in agriculture: An historical perspective. In S. Arapostathis \& G. Dutfield (Eds.), Knowledge management and intellectual property. Concepts, actors and practices from the past to the present (pp. 252-272). Queen Mary studies in intellectual property series. Cheltenham: Edward Elgar Publishing.

Louwaars, N.P., Tripp, R., Eaton, D., Henson-Apollonio, V., Hu, R., Mendoza, M., ..., \& Wekundah, J. (2005). Impacts of strengthened intellectual property rights regimes on the plant breeding industry in developing countries. A synthesis of five case studies. A study commissioned by the World Bank. Wageningen: Wageningen UR.

Malaysia. (2004). Protection of new plant varieties Act. Retrieved from $\mathrm{http}: / /$ www.wipo.int/wipolex/en/details.jsp?id=3143

Malaysia. (n.d.). Plant variety protection system in Malaysia. Retrieved from http://pvpbkkt.doa.gov.my/Publications/InfoPVP-Eng.pdf

Maredia, M.K., Howard, J.A., Boughton, D., Naseen, A., Wanzala, M.N., \& Kajisa, K. (1999). Increasing seed system efficiency in Africa: Concepts, strategies and issues. Michigan State University international development working paper. East Lansing Michigan: Department of Agricultural Economics MSU.

Organization of African Unity (OAU). (2000). African model legislation for the protection of the rights of local communities, farmers and breeders, and for the regulation of access to biological resources. Retrieved from http://www.cbd.int/doc/measures/abs/msr-abs-oau-en.pdf.

Philippines. (2002). Plant variety protection act. Retrieved from http://www.wipo.int/wipolex/en/text.jsp?file_id=225014

Rangnekar, D. (2002). Access to genetic resources, gene-based inventions and agriculture. Study paper 3a. Retrieved from http://www.iprcommission.org/graphic/documents/study_papers.htm

Southern African Development Cooperation (SADC). (2012). Draft protocol for the protection of new varieties of plants (plant breeders' rights) in the southern African development community region. Retrieved from http://www.ip-watch.org/2013/04/05/african-regional-plant-variety-protection-draft-legislation-raises-protes $\mathrm{t} /$

The Crucible II Group. (2000). Seeding solutions. Volume 1. Rome: IDRC, IPGRI \& DHF.

United Nations (UN). (1992). Convention on biological diversity (CBD). Retrieved from http://www.cbd.int/convention/text/

United Nations (UN). (2010). Nagoya protocol on access to genetic resources and the fair and equitable sharing of benefits arising from their utilisation to the convention on biological diversity. Retrieved from http://www.cbd.int/abs/text/

Wiggins, S. (2009). Can the smallholder farmer model deliver poverty reduction and food security for a rapidly growing population in Africa? Paper for the FAO expert meeting on how to feed the world in 2050, 24-26 June, Rome.

World Trade Organisation (WTO). (1995). Agreement on trade-related aspects of intellectual property rights (TRIPS). Retrieved from http://www.wto.org/english/tratop_e/trips_e/t_agm0_e.htm

Zambia. (2007). Plant breeder's right act. Retrieved from http://www.wipo.int/wipolex/en/details.jsp?id=12974 


\section{Notes}

Note 1.34 of the 49 countries in the UN list of LDCs are found in the African continent.

Note 2. Or until the moment that a particular country ceases to be in the least developed category if that happens before 2021. LDCs can seek further extensions of the transition period.

Note 3. Only Botswana, the Gambia, Mozambique, Somalia and South Africa have not signed the ITPGRFA.

Note 4. E.g. replacing the UPOV standards for uniformity and stability by 'identifiability' may make it much more difficult to release a new variety with some improvements on a protected heterogeneous variety, as it may not be easily identifiable.

Note 5. The dichotomy between both viewpoints is thoroughly described in many places. See e.g. Kloppenburg (2005), or African Centre for Biosafety (2012) in the context of the current harmonisation processes in Sub-Saharan Africa.

Note 6. Also, three of the five countries studied in the report subscribe to the UPOV '78 Act and not the UPOV '91 Act, i.e. Kenya, China and Argentina.

Note 7. During the fourteenth session of the Council of Ministers of ARIPO this possibility was indeed discussed and several member countries send in a list of agricultural and vegetable crops for which there is an historical common practice of seed saving in the country, plus the acreage that defines a smallholder farmer in their territory (ARIPO, 2013c).

Note 8. This section is based on De Jonge (2013).

Note 9. And because the UPOV secretariat and other international organisations in support of the UPOV system do provide much needed technical and financial assistance.

\section{Copyrights}

Copyright for this article is retained by the author(s), with first publication rights granted to the journal.

This is an open-access article distributed under the terms and conditions of the Creative Commons Attribution license (http://creativecommons.org/licenses/by/3.0/). 